\title{
ANALYSIS OF RUSSIAN UGS CAPACITY IN EUROPE
}

\author{
A. ARISTOVA ${ }^{1,2} \&$ O.T. GUDMESTAD ${ }^{3}$ \\ ${ }^{1} \mathrm{PhD}$ student, Gubkin Russian State University of Oil and Gas, Russia. \\ ${ }^{2}$ Visiting PhD student, University of Stavanger, Norway. \\ ${ }^{3}$ Professor, University of Stavanger, Norway.
}

\begin{abstract}
Gas is the fuel of choice in Europe for heating, and many expect that gas consumption will continue to increase in the future. On the contrary, European indigenous production decreases, yielding needs to import natural gas primarily from Russia. Travelling long distances from production sites, gas deliveries come by pipelines. Most of them, having operated for decades, have almost depleted their design lifetime, and before long will tend (or have already implemented) to reduce nominal flow pressure and thus flow capacities. To compensate sufficiently for gas peak demands avoiding long, costly and sometimes not practical procedures of changing out pipes, it is suggested to examine the effect of gas storage at European strategic locations to ensure the balance between gas demand and supply.

Along with storing gas in a liquid form as LNG, stipulated by need in spacious plants and infrastructure, Underground Gas Storages (UGS) near to the customers are studied and are seen as the most practical way of natural gas preservation in a gaseous form. Conditions provided, pressurized gas is held in underground facilities at key locations, so that it can rapidly be transported to desired regions.

Depending on a number of factors, and to suit the different gas supply needs, various types of UGSs are distinguished as follows:
\end{abstract}

- Gas storage in depleted fields.

- Gas storages in a water-bearing structures.

- Gas storages in salt dome formations.

The paper outlooks UGSs across Western and Eastern Europe with focus on the available capacity of the biggest gas supplier to EU- Gazprom Group Company and its storage capacities. An investigation is done to demonstrate the recent change in storage volumes rented and owned, and change in the geography of storages involved.

Applying technical and economic criteria, the study shows a need of Russian gas to Europe and a need of European UGS facilities for Russian gas.

Keywords: European gas demand, Russian gas export, underground gas storage.

\section{INTRODUCTION}

Underground gas storages (UGS) furnish prompt contingent gas transportation where it is needed to ensure gas market flexibility. This is of even more importance when gas supply is required at remote locations from the production sites or LNG plants. The UGS hence become economically valuable units for spacious countries and locations with irregular gas consumption and non-uniformly distributed hydrocarbon production sites. In fact, the storages are connected to export trunk pipelines and, if needed, can facilitate urgent gas deliveries to European countries, as they are located much closer to the end users than the production sites, contributing to:

- Reducing the effect of seasonal inequality of consumption.

- Controlling daily fluctuations in gas withdrawal. 
- Dealing with peak consumption.

- Compensating during shortfalls in deliveries.

- Preparations for abnormally cold winter.

- Smoothing interruptions in gas transmission lines.

- Accumulating long-term natural gas reserves in case of force majeure.

Besides an obvious technical need in UGSs, they are also widely used as economical and/or contractual means to:

- Reduce transit risks.

- Increase sales volumes by setting up short-term and mid-term contracts.

- Keep supplies flexible and reliable during peak-periods.

- And therefore sustain a positive brand image.

The above demonstrates the role of UGSs' development in European economics in present days, which is hard to overestimate especially if the storage application domain can be enhanced. This study specifically addresses how UGS capacities would render support to gas supplies if the supply becomes insufficient, conditioning increase in gas demand and handle any substantial reduction in delivery pipes' capacities with time. USGs affect a considerable share of Russian gas export interfacing production sites in Siberia and European western gas hubs. This paper includes an overview of existing underground storage capacities of Russian gas in Europe and FSU countries along with the central part of Russia. Data analysed would give an estimate on gas underground storages' potential contribution to volumes in case of gas delivery shortfalls.

\section{TECHNICAL ASPECTS OF THE UGS FACILITIES}

The underground storage facilities are characterized by their storage capacities and flow rates determining how much and how fast gas can be supplied. The storage capacity consists of active capacity, which can be withdrawn from the storage plant for use, and cushion gas that is used to maintain minimum required pressure in the reservoir.

Different types of natural gas storage facilities give several ways for operation and execution procedures, which is essential to understand when analysing which of them, are suitable for the purpose of this study:

1. Use of depleted reservoirs in gas and/or oilfields.

Despite the significant volume of the cushion gas requirement for such reservoirs (up to $50 \%$ of the total facility capacity), they are the most widely used underground storage sites because of their worldwide availability and existing infrastructure for their operation: wells, collectors, piping, proximity to trunk lines, roads, facilities, etc. Usually depleted gas fields are spacious and can store vast gas quantities, therefore they are commonly used as seasonal and reserve storage units.

2. Water-bearing structures - Aquifers

Water-bearing structures can be converted into the gas storages if bearing sedimentary rock formation is overlaid with an impermeable cap rock. While the geology of aquifers is similar to depleted production fields, their use in gas storage usually requires more cushion gas $(50 \%-60 \%)$ and greater monitoring of withdrawal and injection performance. Daily output can be enhanced by the presence of an active water drive. 
3. Salt caverns

Salt dome formations are impermeable, that decreases the level of cushion gas up to $20 \%$. The overall capacity of UGSF is much less than of depleted fields and salt caverns are often required to be developed at a high cost as opposed to natural depleted reservoirs. Salt domes, however, provide the unique ability to allow several withdrawal and injection cycles during the year: the gas daily output is only limited by the power-capacity of the gas onshore dry units, and the output therefore might be significantly larger than from permeable formations. All these aspects make them ideal UGS for covering peak consumption.

\section{ROLE OF RUSSIA IN EUROPEAN NATURAL GAS SUPPLIES}

Energy is a key driver for development of any economy today. Therefore, the implemented investments in energy sources have been growing and are forecasted to grow in the future. Natural gas is not an exception. To claim the importance of Russian natural gas supply it is essential to study the past and future trends of gas demand in Europe. Reports from global energy companies and agencies such as IEA, Eurogas, BP [10], Exxon [11], Shell proof this statement.

In the scope of this study statistical reports [1] and BP Review of World Energy [2] were analysed and Fig. 1 was prepared to demonstrate that the EU needs of gas supply have grown from $354.7 \mathrm{bcm}$ in 1994 to $459.7 \mathrm{bcm}$ by 2014 . This trend together with multiple articles written [3-5] forecast gas usage in Europe to constantly increase and is expected to increase by $15 \%$ by low scenario and on $50 \%$ by high scenario by 2035 compared to current level $[3,6]$.

With that said gas supplies in EU is seen to stay on the level of 2013-2014 or even decrease $[3,7]$. This is due to the absence of new gas trunk line projects planned; potential decrease in flow capacity of existing pipelines, soon being in operations longer than their design life time; reduction in indigenous gas production; and new economically attractive alternatives to gas volumes delivered by pipes.

To evaluate Russia's, and specifically Gazprom's, position in world's gas consumption and shares of revenues from export of gas sales, the company's reports [1.2] were analysed and Fig. 2 was plotted. The biggest revenue, comprising a total of 57\%, is still seen from gas sales (to Europe, to FSU countries and to domestic customers), of which $60 \%$ are

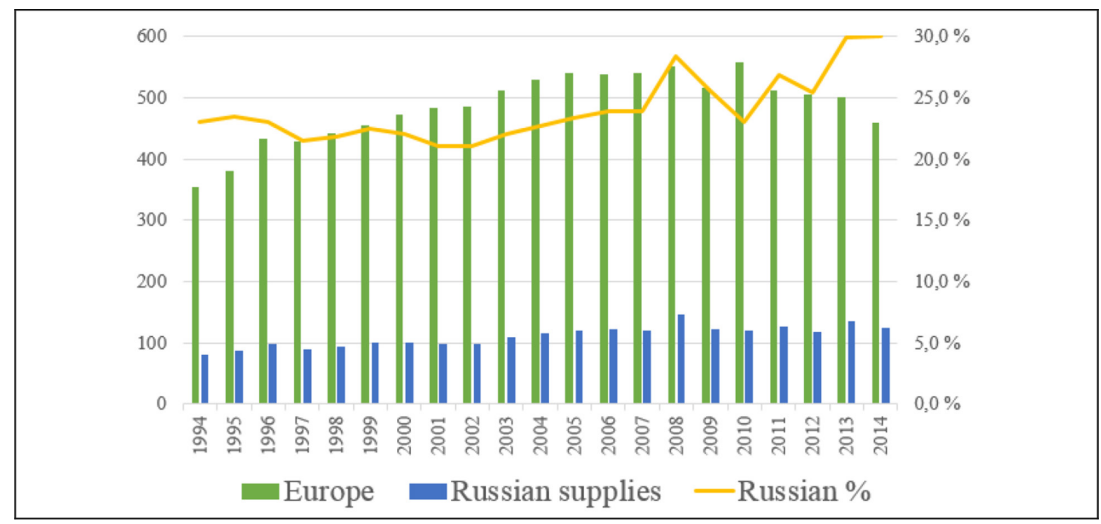

Figure 1: Share of Russian gas supplies in European demand, 1994-2014 (bcm and \%) [1, 2]. 


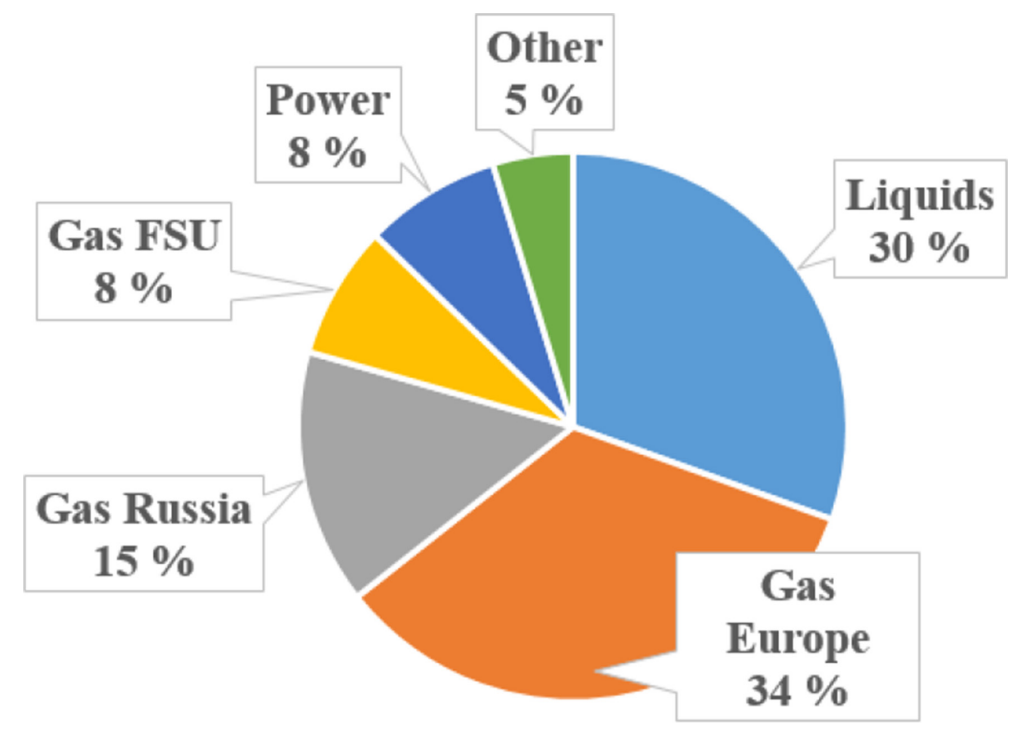

Figure 2: Split of Gazprom Group revenues in 2014.

from natural gas export to the European market. The recent Gazprom Group's deliveries reached around $30 \%$ of EU supplies in average in 2014, and up to 100\% for some European countries.

This implies that both European and Russian gas are mutually dependent for long. And it becomes apparent that increase of gas sales to the European market is a natural way of evolution of the relationship. Yet is it economically efficient for both.

It is assumed that for nearest future Gazprom will continue supplying annually as much as it has been since 1994 to 2014 at a level of $25 \%$ and $30 \%$ as the low and high case scenarios, respectively of total European natural gas demand. With its forecasted increase, this means a required growth in Russian gas export to Europe from 146.6 bcm in 2014 [8] to 158,6 bcm (low case) or 172,4 bcm (high case) by 2035 .

It is therefore reasonable to conclude, that with existing trunk lines operated close to their maximum flow capacities' limits, and unless they are changed out, new lines are built, or an alternative mean of gas supply is found, Gazprom will struggle to facilitate the supply growth expected.

Below chapters overview storage volumes of UGSs in Gazprom's use per today in Europe, Former Soviet Union (FSU) countries and central parts of Russia in order to investigate an opportunity of surplus gas storage to compensate for insufficient supply.

\section{GAZPROM'S UGS CAPACITY IN EUROPE}

Getting a share in UGS capacities is a long process depending on many technical, economic and political factors. Gazprom Group, continuously setting up contracts in Europe, has secured its position in European UGS capacities, starting with 1,4 bcm in 2006 and exceeding $5,0 \mathrm{bcm}$ in 2014 , as could be picked up from the summary plotted in Fig. 3. Note: Data are given on 31.12.2014.

Analysing various data sources when assessing storages capacity numbers, we have observed that data related to non-Group activities or ownership according to Gazprom 


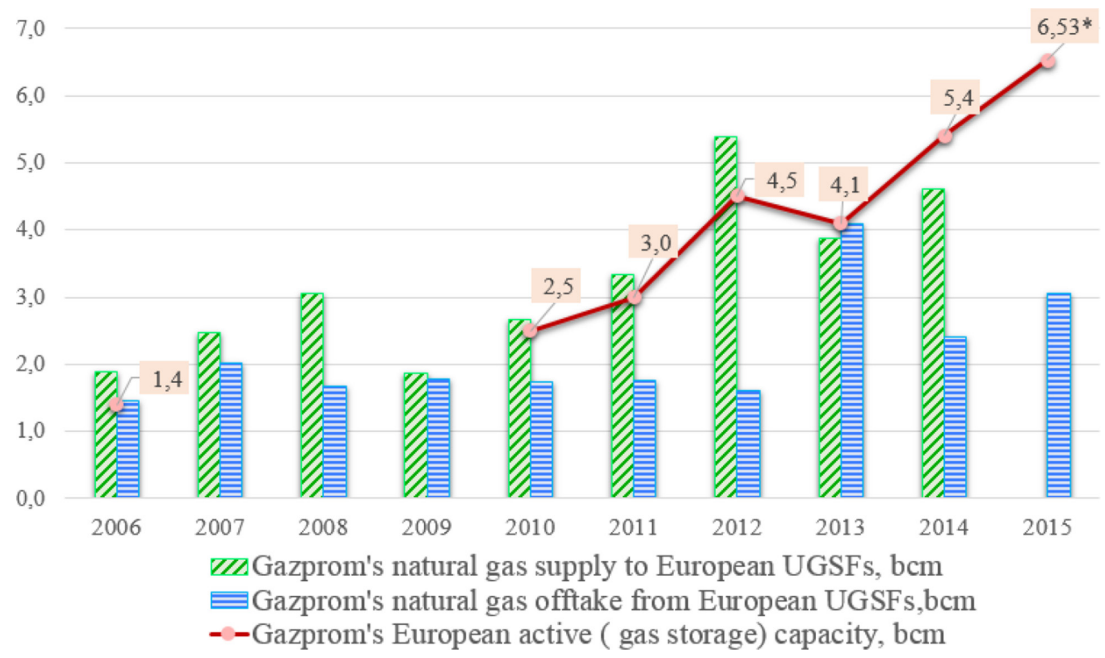

Figure 3: UGS activity in Europe by Gazprom Group, 2006-2015, bcm.

Group's official reports sometimes exceeds numbers from other European sources. Therefore, here and below the data usage priorities were set up as follows:

- Gazprom Group reports: in-house figures.

- European agencies: local data and analysis of the storage volumes involved in the study.

- Gazprom Group reports: estimates and analysis.

Breaking the $5.0 \mathrm{bcm}$ bar and achieving the 2014 goal [8] have induced the Company to expand and maintain storage capacity of minimum 5\% of annual exports by 2030. In 2014, for example, the total current existing active gas storage capacity in the region attained $6.53 \mathrm{bcm}$, which was comfortably close to the aimed 5\% of Gazprom's natural gas export to Europe comprising $7.33 \mathrm{bcm}$.

At 31.12.2014 the stored gas volumes available for the Gazprom Group were distributed between key UGSs locations:

- Austria (Haidach, UGSFs of RAG ES and OMV) - $2.30 \mathrm{bcm}$.

- Germany (Rehden, Katarina, UGSFs of VNG and Vitol) - 1.17 bcm.

- UK (UGSFs of Vitol, Humbly Grove) $-0.23 \mathrm{bcm}$.

- Serbia (Banatsky Dvor UGSF) $-0.23 \mathrm{bcm}$.

- Hungary (UGSFs of MFGK) $-0.70 \mathrm{bcm}$.

- Netherlands (Bergermeer UGSF) - $1.90 \mathrm{bcm}$.

New perspective and ongoing UGSs construction projects such as expanding the Katarina site's salt caverns, construction of Etzel (in Germany) and Damborice (in Czech Republic) UGSs, positively demonstrate the possibility for Gazprom Group to increase storage capacities in EU, keeping up with goal levels set and even outstripping the target if deemed necessary.

There are different ways to access UGSF, which have their pros and cons. Thus, one may prefer to own facilities, rent them or set up special case-to-case storage agreements. Based on 


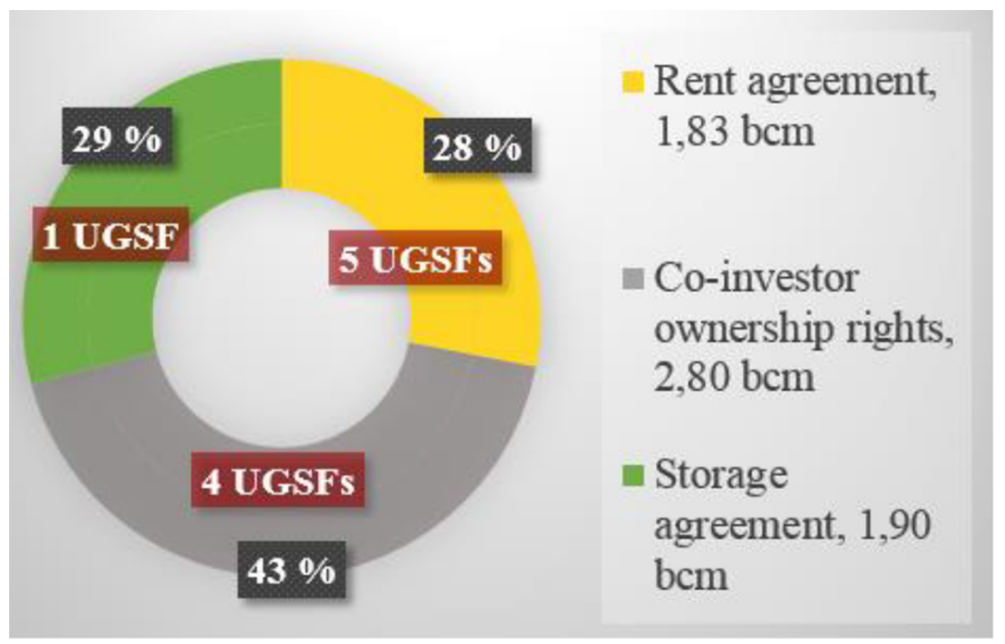

Figure 4: Basis of storage by Gazprom Group in Europe on 31.12.2014, \%.

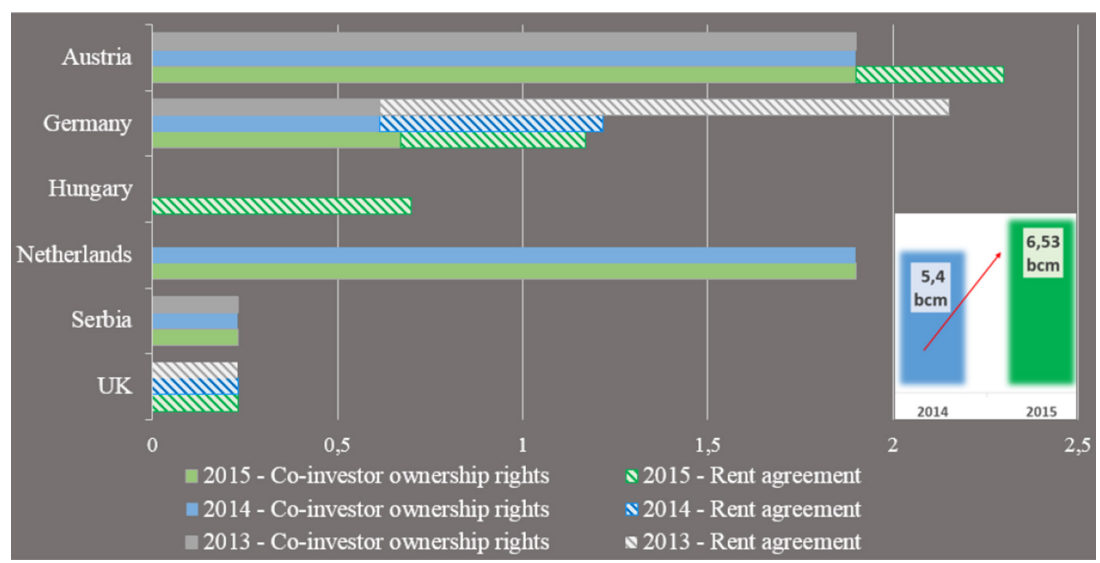

Figure 5: Gazprom's active storage capacity by European countries and basis of storage in 2013-2015, bcm.

data analysed [8, 9] and summarized in Fig. 4, a split between the types of Gazprom's UGS contracts in EU is depicted, where $100 \%$ correspond to existing active capacities of $6.53 \mathrm{bcm}$.

It could be noticed that Group prioritizes to have access to UGS network and infrastructure facilities in company's stake, reducing contractual risks, and dividing the remainder equally between rental and storage agreements.

With a look onto Gazprom's storage capacities distribution between European countries (Fig. 5), it is notable that rental agreements stipulate constant storage gas quantities and serve to cover seasonal fluctuations in North-West of Europe.

Yet, it is remarkable that the overall storage capacities, including the ones on co-investor ownership rights and special agreements, have grown by $20 \%$ for the last few years. This is primarily thanks to expanding existing short-term rental contracts and having access to a new UGS in Hungary, which demonstrates the flexibility and fast track nature of rental agreements on one side, and ensures reliability in the long term prospective on the other. 


\section{GAZPROM'S UGS CAPACITY IN FSU COUNTRIES AND CENTRAL PARTS OF RUSSIA}

The study has revealed that the Group's subsidiaries own three UGSFs in the FSU countries, namely in Belarus (the Pribugskoye, Osipovichskoye and Mozyrskoye storage sites) with a total of $1.20 \mathrm{bcm}$ working capacity. Additionally Gazprom rents volume capacities in Latvia; the Inchukalnskoe UGSF (1.90 bcm), for covering Baltic countries energy needs, and owns a storage in Armenia, which is not considered in this work because of the significant remoteness from European markets.

In order to provide secured internal supplies and ensure a unified gas supply system in Russia, Gazprom operates 26 UGSFs with a total active capacity up to $71.10 \mathrm{bcm}$ on the territory of the country. However, there are only 7 storage sites in the interest of the study, with $15.83 \mathrm{bcm}$ active capacity in the European part, located near major gas consumption regions: Kaliningrad, Saint-Petersburg and Moscow.

Despite formidable storage gas volumes, these facilities are mostly operated to satisfy local gas demand.

On a basis of the discussed Gazprom's share in UGS capacities located in the western part of Eurasia a sensitivity analysis is suggested.

\section{ANALYSIS OF GAZPROM'S ACTIVE UGSS CAPACITIES}

The estimated Gazprom's active UGSs capacities included in the scope of this study above, have been further divided into 3 categories based on the terms of different contracts' sustainability, robustness in long term prospective and risks to set up or terminate storage gas quantities:

- The least reliable UGSs volumes are assigned to those under renting agreements which are usually signed for short-term periods. These contracts are signed with uncertain terms for long-spanning forecasts and hence, in this work, deemed as having a maximum risk of contracts termination. Despite being unsteady, the UGS volume in this group cannot be completely neglected in the analysis as it represents a substantial share of the stored gas' overall quantities, which, as shown in Section 4, can be expanded as fast as it can be decreased.

- Volumes with moderate forecasting reliability and risk are taken as a percent of own UGS reserves in the central part of Russia and Belarus. Primarily designed for local needs, the storages repetitively run dry, and most of the inbound gas is going to cover domestic shortfalls. However, statistical analysis of the 15-years data on gas injection/withdrawals in these storages, has shown that, at average, $10 \%$ of the total volumes remain stored untouched. These volumes are usually spoken of as" operating reserves" and generally are not withdrawn. If an immediate need in these quantities is not seen, these volumes can be used to back up sales to the EU for the purposes suggested in this study, and compensated for with the extra volumes of gas injected at a later stage.

- The most reliable quantities are considered as the ones owned by Gazprom in European UGS on the basis of co-investor agreements.

Calculated and categorized capacities are illustrated in Fig. 6, all together attaining $10.13 \mathrm{bcm}$. Under our assumption these volumes can be relied on in a distant future, they marginally exceeds the announced 5\% of Gazprom's annual exports goal. Excessive volumes reach $2.20 \mathrm{bcm}$ and $1.51 \mathrm{bcm}$ in low and high case scenarios. respectively. 


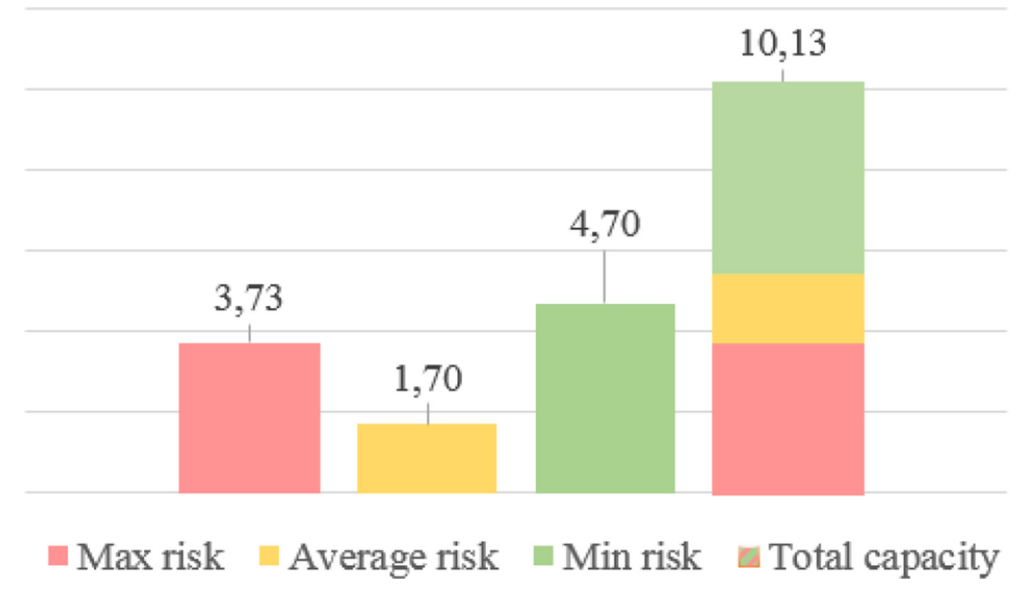

Figure 6: Gazprom's active UGSs capacities by risk / reliability analysis, bcm.

The following findings could be observed:

- The today's UGSs capacities are forecasted adequate to cover the European gas needs in present condition or conditions of constantly increasing gas demand.

- The excess UGS capacity available can only insignificantly compensate for any gas trunklines' reduction in capacities. A further study is required to demonstrate how much extra UGS gas would be needed to sufficiently cover potential shortages caused by increased demands and potential pipeline flow capacity reduction.

- It is apparent that when only volumes with average and minimum risks are accounted for, there are not enough reserves to support the storage goals and the forecasted scenarios. In order to secure this part of supplies, the required capacities should be in the reliable zone. It is therefore expected that Gazprom will continue to seek ways and options to own UGS capacities in Europe.

- Additional volumes (both in UGS and delivered by pipes) for European needs can be gained if the structure of the Russian domestic natural gas supply and administration is revised. Alternative energy sources and alternative ways of their implementation would make it possible to optimize the energy balance of the country.

\section{CONCLUSIONS AND FURTHER STUDIES}

The study has shown that if gas supplies to Europe stay on the present level, and in particular in the case of a steadily growing European demands, the use of UGS becomes a reliable solution to counter-balance possible shortfalls, making natural gas a sustainable energy source for end-users for long.

Gazprom Group is a major long-term gas supplier to the European market, which operates UGS capacities under a wide range of agreements, different in nature. A sizable part of the available gas storage facilities, located in strategic locations in EU countries, is concluded to be secured marginally comfortable contractually to secure European needs and to meet any excessive demand. It is, furthermore, concluded, that in the event Russian gas supplies to Europe should drop, the storage volumes become insufficient, and new storage facilities are needed to be established, preferably based on long-term co-investor rights. 
Further works are suggested to study flow capacities of trunk pipelines delivering Russian natural gas to European borders, assess the level of their wear and prepare technical estimates of possible gas quantity reduction to accurately demonstrate how much gas Europe potentially will lack in the near future. Local European pipeline networks transferring volumes through European countries to UGSs' locations should then be considered in order to find additional storage sites and to identify potential locations for their establishment.

\section{REFERENCES}

[1] Eurogas, Statistical Report 2015, available at: http://www.eurogas.org/uploads/2016/ flipbook/statistical-report-2015/index.html

[2] BP, Statistical Review of World Energy, 2015 available at: http://www.bp.com/content/ $\mathrm{dam} / \mathrm{bp} / \mathrm{pdf} /$ energy-economics/statistical-review-2015/bp-statistical-review-of-worldenergy-2015-full-report.pdf

[3] Jones, D., Dufour, M. \& Gaventa, J., E3G, Europe's Declining Gas Demand: trends and facts on European Gas Consumption, 2015, available at: https://www.e3g.org/docs / E3G_Trends_EU_Gas_Demand_June2015_Final_110615.pdf

[4] Dickel, R., Hassanzadeh, E., Henderson, J., Honoré, A., El-Katiri, L., Pirani, S., Rogers, H., Stern, J. \& Yafimava, K., Reducing european dependence on russian gas, OIES, 2014, available at: http://www.oxfordenergy.org/wpcms/wp-content/uploads /2014/10/ NG-92.pdf

[5] Honoré, A., The outlook for natural gas demand in europe, OIES, 2014, available at: https://www.oxfordenergy.org/wpcms/wp-content/uploads/2014/06/NG-87.pdf

[6] Eurogas, Roadmap, 2011 available at: http://www.eurogas.org/uploads/media/Eurogas _Roadmap_2050_-_Explanatory_Note_13.10.11_01.pdf

[7] IEA, Energy Efficiency Market Report 2015, available at: http://www.iea.org/ publications/freepublications/publication/MediumTermEnergyefficiencyMarketReport2015.pdf

[8] Gazprom Annual Reports 1998-2015, available at: http://www.gazprom.com/ investors/ disclosure/reports/2015/

[9] Factbook, Gazprom in figures 2010-2014, available at: http://www.gazprom.com/f/ posts/ 29/761233/gazprom-in-figures-2010-2014-en.pdf

[10] BP, Energy Outlook, 2016, available at: https://www.bp.com/content/dam/bp/pdf/ energy-economics/energy-outlook-2016/bp-energy-outlook-2016.pdf

[11] ExxonMobil, Outlook for Energy: view to 2040, 2013, available at: http://www. slideshare.net/MarcellusDN/exxonmobil-2013-the-outlook-for-energy-a-view-to-2040 